\title{
Cylinder-to-cylinder and cycle-to-cycle variation in combustion process in radial aircraft engine
}

Cycle-to-cycle variation in combustion in a single cylinder of a radial engine has an impact on that in others and the entire engine. Steady-and transient-state engine operation was investigated, and the transient states were generated by cyclic changes in the timing of fuel injection to a given cylinder, having others operated on the same mixture composition. The measurement of pressure in the combustion chamber allowed for specifying indicated mean effective pressure (IMEP) in all cycles. The time series of IMEP were studied with mathematical techniques of non-linear dynamics, i.e. a wavelet transform and a multifractal analysis. Controlled disturbances in mixture composition in a single cylinder can have an impact on certain cylinders only. Cylinders 3, 5, 7 and 9 are most responsive to such disturbances, which proves their least cycle-to-cycle variation in combustion.

Key words: radial engine, combustion, non-uniformity, cycle-to-cycle variation, wavelet analysis, multifractal analysis

\section{Introduction}

Cycle-to-cycle variations in cylinder operation is typical of multi-cylinder engines. Performance of a next cylinder and combustion in a given cylinder are impacted by a design of a combustion chamber [1], pistons, a pistoncrankshaft system, location of spark plugs and arrangement of cylinders [14]. Cylinders in the radial engine are arranged radially around the crankshaft, with their axes intersected at one point. Intake lines, connecting the compressor and heads of the carburetor-powered engine, are identical in shape but supply a differently composed airfuel mixture, which is due to gravity acting on fuel drops and a fuel film. A mixture and fuel film move clockwise (lower cylinders) or counterclockwise (upper cylinders) with respect to gravity. The compressor moves by several degrees a fuel film in the same direction as its own rotation. Upper cylinders receive a lighter but lean mixture, whereas lower ones a heavier but richer mixture. A mixture of the air-fuel ratio larger than 1 , i.e. $\lambda>1$, or a lean mixture burns longer and makes an excessive increase in temperature of combustion chamber elements. As a result, it is difficult to maintain an appropriate head temperature in air-cooled radial engines and if temperature increases, knock occurs. The research by an American company, Radial Engines Ltd., a manufacturer of seven-cylinder radial engines Motors Jacobs R755B2 (202 kW) confirms an irregularly distributed mixture in cylinders, having analysed temperatures of exhaust gases in cylinders [22].

Multi-point fuel injection is the method to stabilize a mixture in steady states and to limit cycle-to-cyle variations in the operation of the combustion engine. Unfortunatelly, supplying the radial engine by injection cannot entirely be a solution here because more than $90 \%$ of fuel after injection settles down on intake system walls and only $10 \%$ of it reaches the cylinder in the first operating cycle. The rest of fuel evaporates with delay or reaches the combustion chamber in the liquid phase. Equilibrium, after which the mass of fuel injected into the intake system is the same as the mass of fuel which reaches the cylinder, is achieved after 6 operating cycles [19].
The irregular distribution of IMEP between cylinders in the ASz-62IR supplied by injection of $\mathrm{Pb} 95$ and Avgaz $100 \mathrm{LL}$ is discussed in [10].

Cycle-to-cycle variation is also impacted by the distribution of temperature on a cylinder surface. In the aircooled radial engine, the cylinder head and liner are heated unevenly.

Cycle-to-cycle variation in the multi-cylinder engine can result from irregularly distributed any of the above factors in cylinders [15] as well as non-linear entire combustion (several possible courses of this process). The way the crankshaft-piston system in the radial engine is designed can differentiate a piston stroke. Each cylinder slightly differs in a degree of its compression and displacement.

The phenomenon of cylinder-to-cylinder variation is also impacted by cycle-to-cycle variation in combustion. The cyclical nature of processes follows from the nature of processes in the engine, i.e. the principle behind the operation of the piston internal combustion engine. Cycleto-cycle variation in combustion may result in instability which reduces engine power $[9,11]$.

Cycle-to-cycle variation in combustion is especially high in SI engines. The sources of pressure oscillation were first classified by Heywood (the 1980s) as a degree of turbulence in the cylinder during combustion, a diversity of the amount of air and fuel, and the rest of exhaust gas in the cylinder as well as the local distribution of mixture around the spark plug [8]. The changed quality of a mixture has an impact on cycle-to-cycle variation [12].

A mathematical technique enables us to study time series and predict the future from the past. Data collected as time series give information on the past. Predicting the future from a statistical analysis is predicting possible behaviours. Importantly, predicting changes and tendencies can also become complicated if an investigated dynamic system has many solutions, which is a fundamental feature of non-linear systems. Slightly modified initial conditions or parameters of the system in non-linear systems can lead to a significantly modified response of the dynamic system, e.g. an internal combustion engine and its combustion. 
Other interesting effects to be expected in non-linear systems are time synchronization and spacial location.

Importantly, the previous studies on the phenomena of irregularity and cyclical variation chiefly investigated automotive liquid-cooled engines and a single cylinder only. Unlike the radial engine, their intake ducts are arranged gravitationally.

The author proposed [4] a physically proven non-linear map as a model of cylinder-to-cylinder variation in the SI engine. He also discussed an approach of symbol rates statistics to digitize model and research time series. Other authors attempted [3] to synchronize cylinder-to-cylinder variation in automotive high-capacity engines. Cycle-tocycle variation in combustion in the carbureted radial engine is investigated [2] to show significant differences in combustion in each cylinder and confirm cylinder-tocylinder variation.

The methods to investigate time series of cylinder pressure with non-linear dynamics are efficient and allow for an in-depth understanding of an internal combustion engine. Cycle-to-cycle variation was examined by a number of researchers with the methods of non-linear dynamics to find out nonlinear aspects of variation [5]. The works using a wavelet transform and a multifractal analysis also followed this tendency $[13,18]$.

By investigating pressure in a given cylinder, it can be said that pressure clearly changes over time, both for its amplitude and frequency. Phase-frequency and timefrequency selections are sensible approaches to study the combustion engine bacause of rapid changes that occur at high frequencies and slow changes in low frequencies. This method is capable of defining positions of a filter on a timefrequency map by a scale factor and a window shift. If a window shifts towards high frequencies, its width decreases, which reduces resolution rate and increases time resolution and the other way round.

Recurrence plots method has been used to distinguish combustion dynamics of a multicylinder aircraft radial engine in the presence of cyclic perturbations in one of cylinders [6]. This paper follows non-linear methods to describe the mode of combustion in each radial engine cylinder. There are applied quantitative methods as a multifractal analysis and qualitative methods as a wavelet transform. These two approaches allowed for investigating an operating cycle in each cylinder and the impact of combustion in a given cyclinder on combustion in others.

\section{Research object and the engine test stand}

The research object is a four-stroke, air-cooled, gasoline aircraft engine - ASz-62IR (Fig. 1), manufactured at WSK "PZL-Kalisz". It is now a drive unit in the following aircraft: An-2, M-18 "Dromader", DHC-3 "OTTER", DC-3 "Dakota", GAF-125 "HAWK" and Y5. Our research engine has 9 radially-arranged cylinders with a total displacement of $29.87 \mathrm{dm}^{3}$. The engine is supecharged mechanically with a radial compressor driven from a crankshaft with a gear of 1:7. The maximum boost pressure is $0.14 \mathrm{MPa}$, and compression $6.4: 1$. The maximum power of approximately $745 \mathrm{~kW}(1,000 \mathrm{hp})$ is achieved at 2,200 rpm. The maximum fuel consumption at take-off power is approximatelly 300 $\mathrm{kg} / \mathrm{h}$. The engine is supplied with 9 electronically controlled injectors that inject fuel into all of the intake pipes.

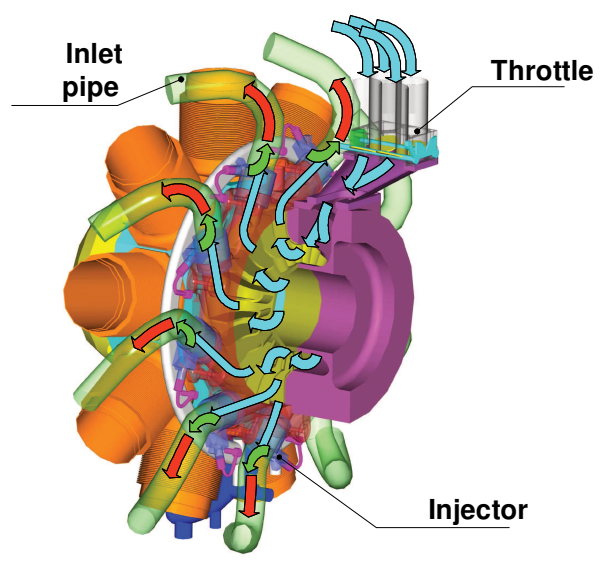

Fig. 1. ASz-62IR supplied by injection system

The engine section has a construction where our research engine is attached (Figure 2). Load is a four-bladed propeller with an adjustable angle of attack. Torque is measured by changing the position of counterweight. The so read reaction torque and regarding the factors behind the test stand enabled us to specify the torque generated by the engine.

To monitor the parameters of its performance, the research engine is equipped with sensors such as 4 pressure transmitters MPX4250 under the carburetor, 2 pressure transducers MPX4250 Motorola in each of the intake pipes at the compressor and head.

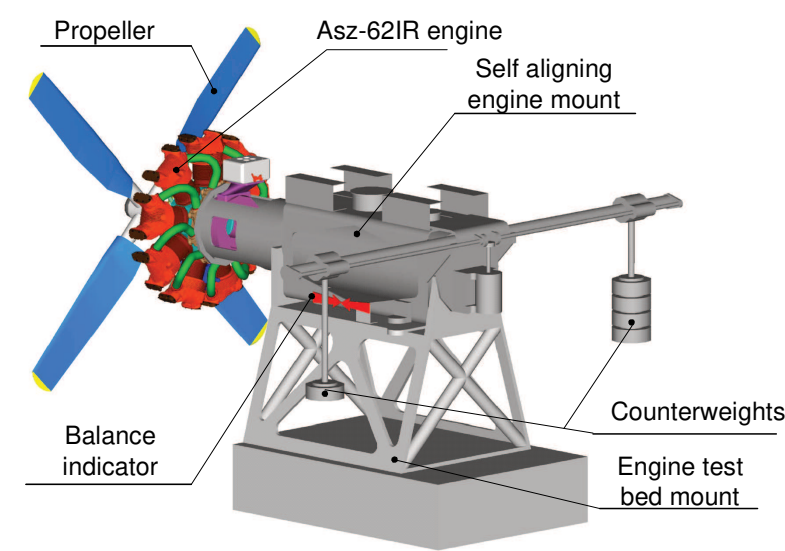

Fig. 2. Schematic of the engine section at the engine test stand

Combustion process was monitored with OPTRAND M $3.5 \times 0.6$ optoelectronic sensors installed in special adapters screwed in the central section of the head. This type of sensor monitors how the intensity of light from two adjacent fibers, one connected to the LED and the other to a photodetector changes. Any changes in the intensity of light received by the photo diode result from changes in the intensity of light reflected by a steel membrane which is deformed by pressure [21].

The cylinder pressure sensor consists of a pressure transducer connected to a signal transducer by means of an 
optic fiber. The measurements of combustion pressure in each cylinder were synchronized and automatically performed in line with the signals from the magneto-inductive sensor to monitor engine speed and the position of a Honeywell crankshaft. Pressure signals were amplified and sent to an acquisition card to be archived on a hard drive.

\section{Research methodology}

\subsection{Test stand research}

The operation of the engine was studied in steady states, at constant speed and load as intake manifold air pressure. The measurements were performed for a middle operating range, i.e. speed $n=1,770 \mathrm{rpm}$ and load ranging between a propeller characteristics and a full power characteristics at $\mathrm{p}_{\mathrm{k}}=0.094 \mathrm{MPa}$. At the measuring point, the engine generates a power of $353 \mathrm{~kW}$ and fuel consumption per hour is $109 \mathrm{~kg} / \mathrm{h}$ (Figure 3). These conditions correspond to cruise speed of the airframe and are most frequent in operation.

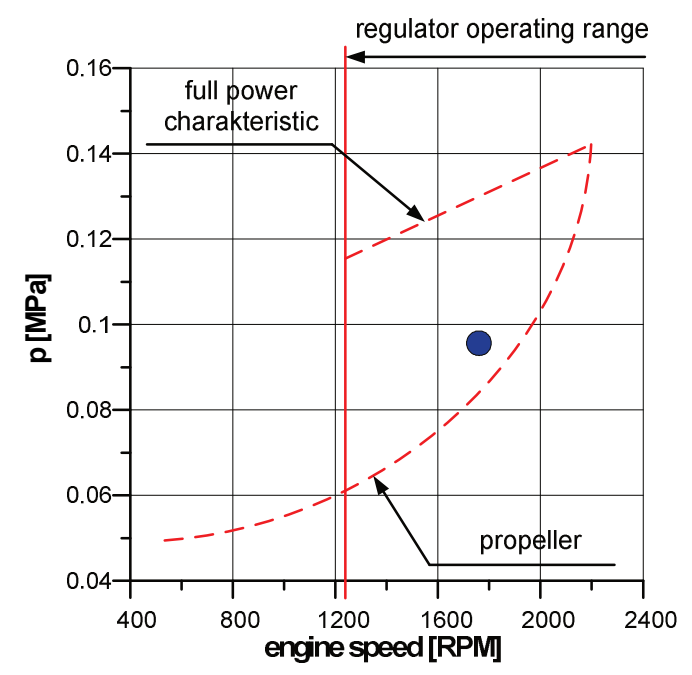

Fig. 3. Operating range and the measuring point [6]

Our transient investigation involved registering cylinder pressure during a case, in which one of considered cylinders was perturbed by changing the injection timing. Each of the cylinders was supplied by a mixture of $\lambda=0.7$. The fuel injection timing was selected so as to obtain a given value of air-fuel ratio. This composition was achieved by selecting fuel injection time as $t_{1}=7.8 \mathrm{~ms}$. One of the cylinders was fuelled in a varying step way by changing the injection time every $10 \mathrm{~s}$ from $\mathrm{t}_{1}=7.8 \mathrm{~ms}$ to $\mathrm{t}_{2}=5.84 \mathrm{~ms}$ according to the diagram given in Fig. 4 [6].

There were 9 measurement series in which a given cylinder was cyclically supplied according to the order of ignitions (Fig. 5). Pressures in 9 cylinders, i.e. 8 of them supplied by a mixture of constant composition and 1 by a mixture of disturbed composition were simultaneously registered at each measuring point.

There were also measurements in which one cylinder was supplied by a mixture of disturbed composition and the others were supplied by a mixture of $\lambda=0.7$. Combustion chamber pressure was measured with a sampling frequency of $22 \mathrm{kHz}$ ( 2 samples per one crankshaft rotation). Then, the IMEP for subsequent 1,000 cycles was calculated from each engine cycle. The surface area of the indicated pressure chart was calculated. A single sample shows measured pressure and displacement. The IMEP of a single cycle can be calculated from the formula:

$$
\operatorname{IMEP}(\mathrm{i})=\frac{1}{\mathrm{~V}_{\mathrm{s}}} \sum_{\mathrm{j}=0}^{\mathrm{n}-1} \frac{\left(\mathrm{P}_{\mathrm{j}+1}+\mathrm{P}_{\mathrm{j}}\right)}{2}\left(\mathrm{~V}_{\mathrm{j}+1}-\mathrm{V}_{\mathrm{j}}\right)
$$

where $\left(P_{j}+P_{1, j}\right),\left(V_{j+1}, V_{j}\right)$ are respectively $j+1$ and $j$-th value of combustion chamber pressure and volume and $n$ is the number of samples per cycle. This means that the calculation of IMEP is coordinated with the crankshaft position. The calculation data included the length of a connecting rod, a cylinder bore and the time of a single cycle.

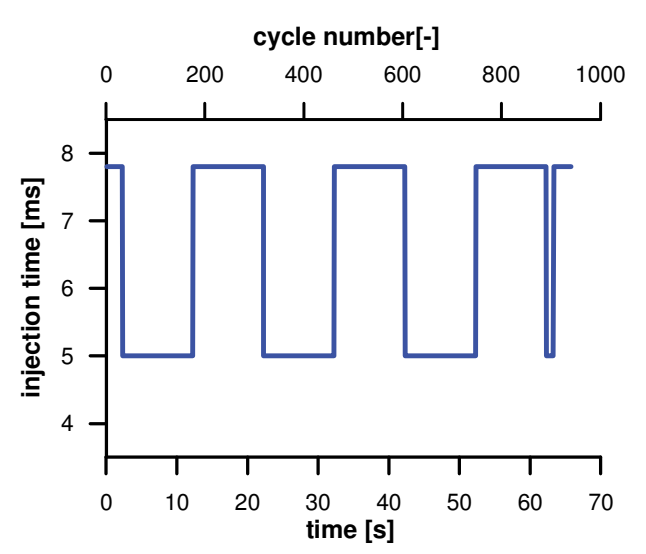

Fig. 4. Diagram of mixture composition disturbance in the individual cylinder [6]

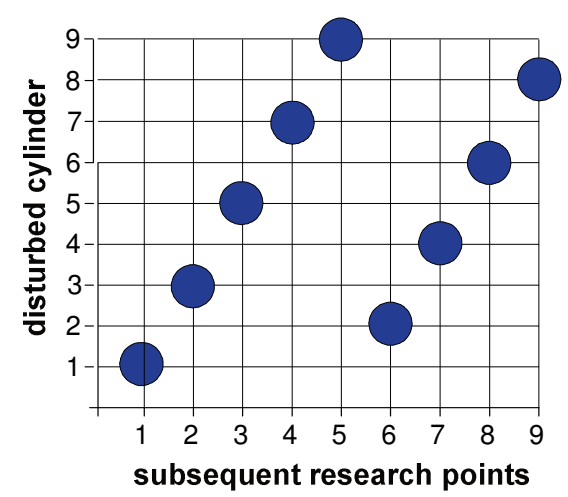

Fig. 5. Order of disturbances in mixture composition in the cylinders

\subsection{Wavelet analysis}

The wavelet transform can use any base function as a base function [17]. The Morlet function is most popular for its simplified mode of calculation. This method resembles a filtration with a constant relative bandwidth $\Delta \mathrm{f} / \mathrm{f}_{\mathrm{s}}$. The parameters of scale a and transposition $b$ determine the location of the filter on the time-frequency map. Bandwidth increases with the $b$ to larger frequencies (frequency resolution of analysis decreases), and then time resolution increases and the other way round. This feature is used in a simultaneous analysis of various high- and low-frequency time steps and rapidly changing processes of low speed. 
The Continuous Wavelet Transform (CWT) analyzed the time series of IMEP. The wavelet transform in relation to a wavelet function $\psi(\cdot)$ is defined as follows:

$$
\mathrm{W}_{\mathrm{s}, \mathrm{n}}(\text { IMEP })=\sum_{\mathrm{i}=1}^{\mathrm{N}} \frac{1}{\mathrm{~s}} \Psi\left(\frac{\mathrm{i}-\mathrm{n}}{\mathrm{s}}\right) \frac{(\text { IMEP(i) }-<\text { IMEP }>)}{\sigma_{\text {IMEP }}}
$$

where $<$ IMEP $>$ is the mean and $\sigma_{\text {IMEP }}$ is a standard deviation. A wavelet $\psi(\mathrm{t})$ is a base wavelet, $\mathrm{n}$ is a scale shift and $\mathrm{S}$ is a positive real number creating the scale. A wavelet power spectrum (WPS) of the time series of IMEP is defined as the square of the absolute value of CWT.

$$
\mathrm{P}_{\mathrm{w}}(\mathrm{s}, \mathrm{n})=\left|\mathrm{W}_{\mathrm{s}, \mathrm{n}}\right|^{2}
$$

Our calculation uses as a base function the complex Morlet wavelet which consists of a flat wavelet modulated by the Gaussian function and is defined by the formula:

$$
\Psi(\eta)=\pi^{-1 / 4} \mathrm{e}^{\mathrm{i} \theta_{0} \eta} \mathrm{e}^{-\eta^{2} / 2}
$$

The value of $\mathrm{q}_{0}$ defines the number of oscillations in the wavelet to control time-frequency resolution. $\theta_{0}=2 \pi \mathrm{f}_{0}$ is defined as a wavelet degree where $\mathrm{f}_{0}$ is a frequency center. Higher $\theta_{0}$ improves frequency resolution but if lower, time resolution improves. Our analysis uses $\theta_{0}=6$. Such an approach results in a time and frequency resolution balance. The scale is also roughly equal to the period so the conditions of scale and time can be interchanged while investigating results.

\subsection{Multifractal analysis}

A multifractal analysis of IMEP oscillation consists of a specific spectrum of time series of IMEP against the Hölder exponent as a function of the Hausdorff distance. Its complexity can be evaluated by means of the width of a multifractal spectrum.

Following the procedure [16], the vicinity of each cycle and along a studied time series of IMEP $(i+\Delta i)$ are investigated to find coefficient hi (incomplete number) capable of determining the corresponding discrepancy:

$$
|\operatorname{IMEP}(\mathrm{i})-\operatorname{IMEP}(\mathrm{i}+\Delta \mathrm{i})| \leq \mathrm{a}_{\mathrm{h}} \Delta \mathrm{i}^{\mathrm{hi}}
$$

Factor $a_{h}$ is related to exponent $h_{i}$ which specifies a local internal separation. Generally, a multifractal analysis is based on a specific spectrum $f(h)$ of all exponents $h_{i}$ and precisely describes a quantitative behavior of a system. Formally, h defines the Hölder exponent and the probability of its decomposition, $\mathrm{f}(\mathrm{h})$, coincides with the Hausdorff distance of a dynamic system.

Figure 6 shows a sample method of specifying critical exponents for time series of indicated pressure when mixture composition was modified in cylinder 1 . The red curve refers to the results from the multifractal analysis using a modified software code [7]. Across it, there is marked a tendency line (blue) calculated from a 4-level polynomial and least squares. The formula of a polynomial was entered into the MATHCAD to find the squares of the equation. Its complexity can be evaluated by means of the width of a specific spectrum, i.e. the value of critical exponents $\Delta \alpha$.

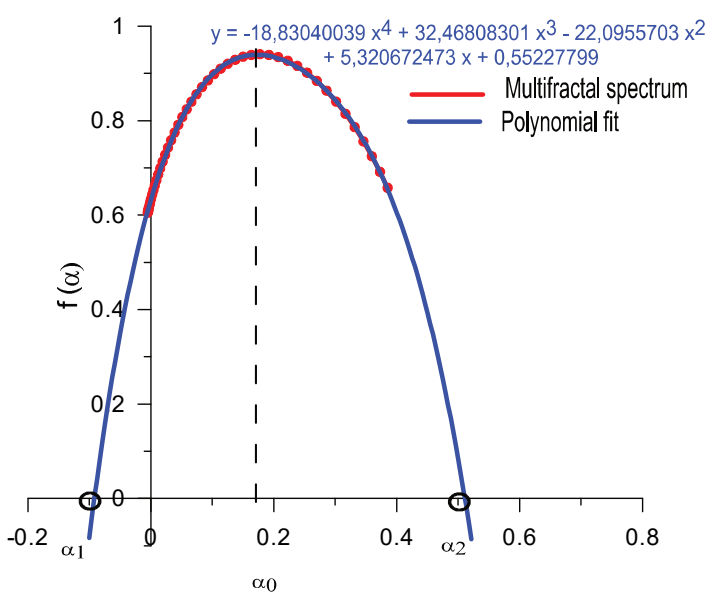

Fig. 6. Sample of a multifractal spectrum with critical exponents $\Delta \alpha$ and its most expected value of $\alpha_{0}$ when mixture composition was modified in cylinder 1

\section{Research results}

In each series of our measurements, from 950 to 1,040 operating cycles were examined. Such a range was selected due to our research method in which the engine was held at a given operating point over a given constant period of time of $1 \mathrm{~min}$. Such a period of time was selected to achieve a minimum of 900 operating cycles but it was limited by the size of the files with the measurements of several quantities to be saved.

IMEP was calculated from each of the registered cycles to create a time series of IMEP. Figure 7 shows a sample of a time series at a given measuring point when the mixture composition was disturbed in cylinder number 5 .

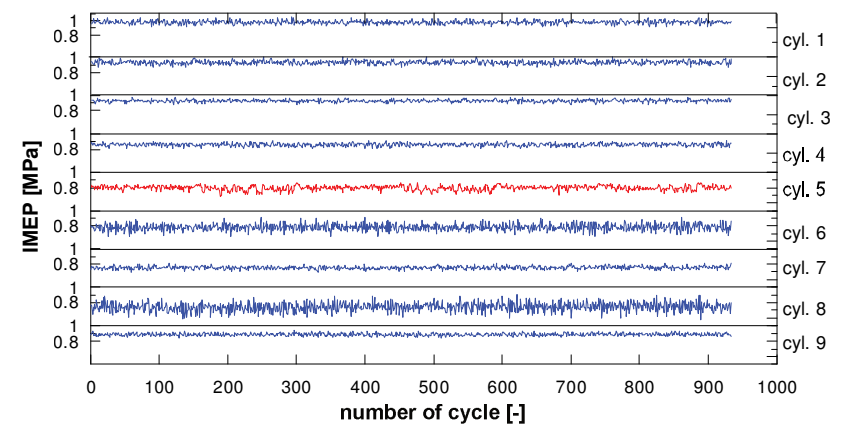

Fig. 7. IMEP time series in subsequent operating cycles when mixture composition was modified in cylinder 5

Figure 8 shows the research results of our MF analysis of the IMEP in the cylinders if the engine was driven by all of the cylinders supplied by a non-modified mixture composition of $\lambda=0.7$. There were specified: a range of critical exponents $\Delta \alpha$ and its expected value $\alpha_{0}$. The dotted line shows the maximum values of the exponents of our MF analysis (case without injection perturbations in cylinders).

Figure 9 shows the research results of our MF analysis with the operation of the engine with one mixture-modified cylinder, marked with the black circle, and the other cylinders supplied by a mixture of $\lambda=0.7$. In addition, the dashed lines marked in all of the charts stand for the maxi- 
mum values of the critical exponents of our MF analysis that occur if the engine is not disturbed by a modified fuel dose supplied into a given cylinder (see Fig. 9). The bottom right section of the figure shows again the research results of our MF analysis but for the modified cylinders only.

The results show that some of the modified cylinders can be distinguished by their extreme values of $\Delta \alpha$ and $\alpha_{0}$. The maximum value of $\Delta \alpha$ for the modified cylinder no. 3 (a black circle) is due to a cyclically disturbed mixture composition.

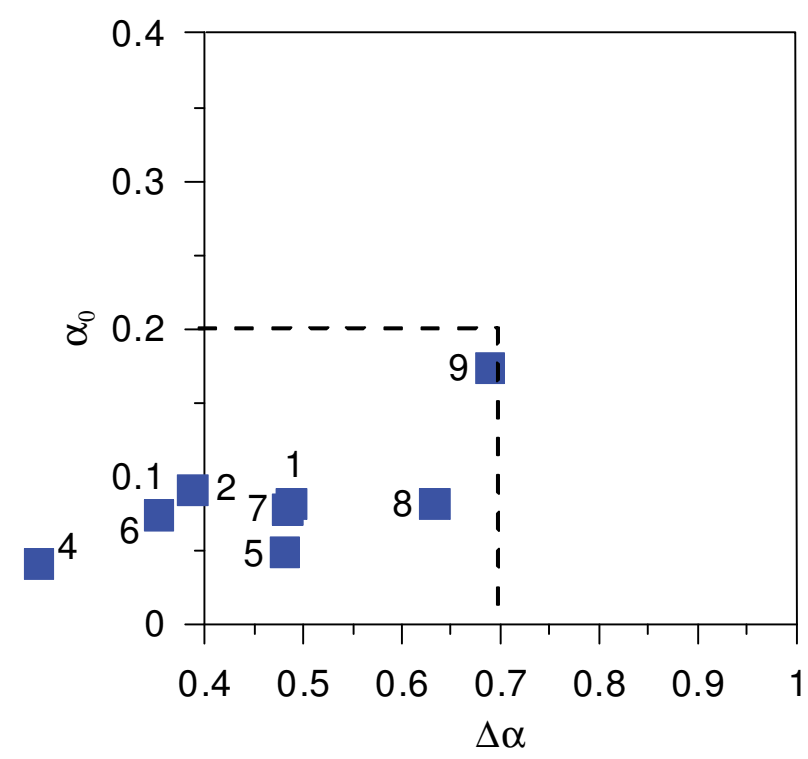

Fig. 8. Comparing an MF analysis of IMEP in the cylinders supplied by a mixture of non-modified composition of $\lambda=0.7$ for $100 \mathrm{LL}$.

Disturbed cylinders no. 3, 5 and 7 show the highest value of $\alpha_{0} \approx 0.3$, which indicates the least negative correlation and a higher correlation of pressure fluctuations. Most of the odd-numbered cylinders supplied by a mixture of modified composition shows large $\Delta \alpha$, which is related to a highly complex course of combustion. The course of pressure during mixture modification have complex response.

If the distributions of MF from Figures 9 and 10 (distributions of MF if no disturbances) are compared, the parameters clearly go beyond maximum $\Delta \alpha \approx 0.7$ and $\alpha_{0} \approx 0.18$. This range always covers from 3 to 4 cases of indicated pressure out of 8 cases of failed cylinders. The repeating courses within this range are the courses of cylinders 6 and 8 (5 repetitions) and cylinders 4 and 5 (3 repetitions). Moreover, if the courses of the disturbed cylinders are investigated only, and despite a disturbance in mixture composition, cylinder 8 still operates as if the engine were not disturbed at all. If cylinder 2 fails, there are two courses (cylinders 8 and 9).

Their presence in the collection means that the IMEP proceeds in a comparable way, i.e. the largest negative correlation and low complexity.
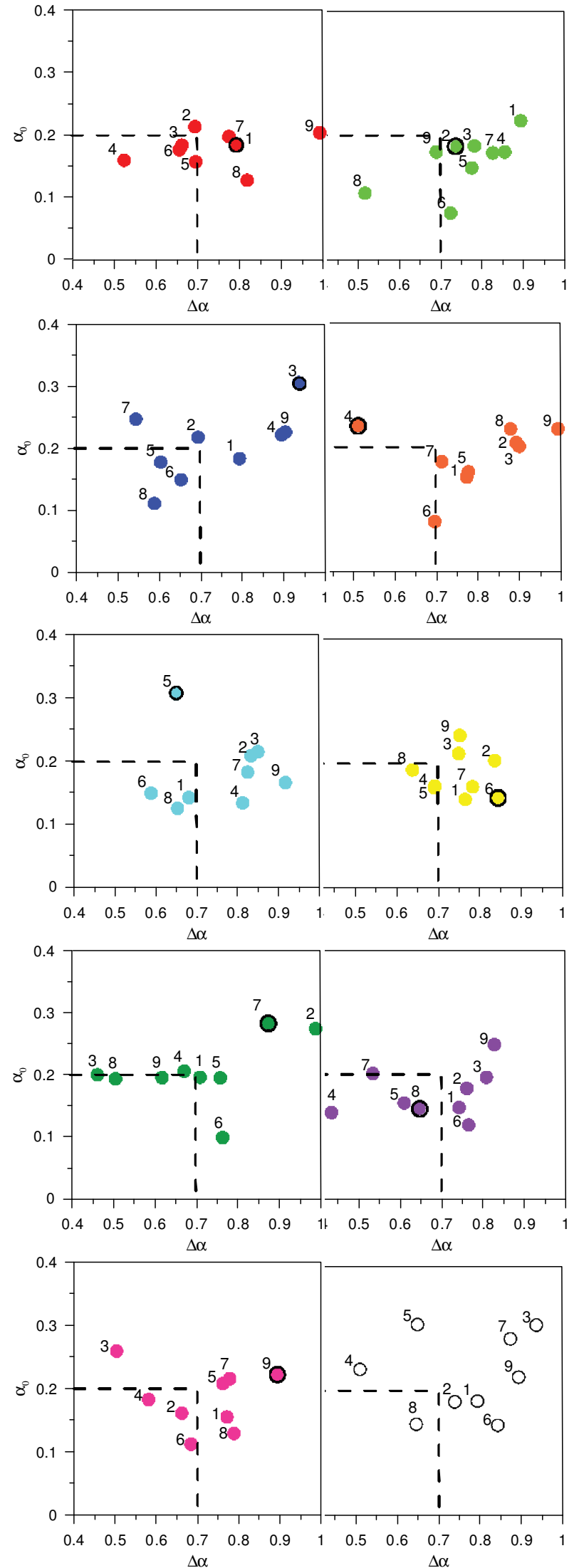

Fig. 9. Results of our MF analysis of the indicated pressure in each cylinder supplied by a mixture of modified composition (black circle), the other cylinders supplied by a mixture of $\lambda=0.7$. The last graph (black points) summarizes the MF analysis for the disturbed cylinders only 


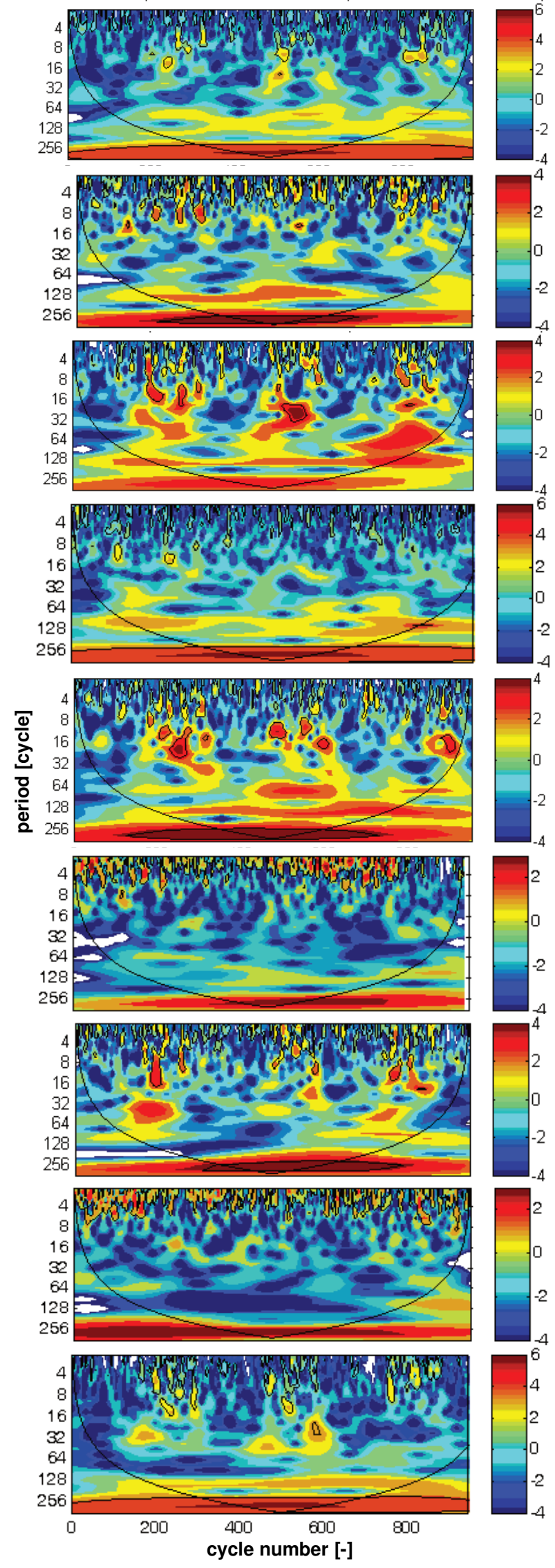

Fig. 10. Wavelet power spectrum for the IMEP in the cylinders supplied by a mixture of disturbed composition and the others supplied by a mixture of $\lambda=0.7$
Cylinder-to-cylinder variation in operation is depicted in the wavelet power spectrum (Fig. 10) showing the pressure changes in the two domains at the same time, i.e. in domains of time and frequency (or the corresponding periods). The horizontal axis shows the subsequent numbers of successive cycles, whereas a vertical one shows a period (the inverse of frequency) in cycles. An associated power of a signal (relative to the option) is marked with colors in the figure. Red indicates the highest level of power, blue the lowest level, and other colors show middle values. The individual colors of the chart inform about dominant periods, which signal is stationary, and what its nature is (growth and disappearance of amplitudes or an intermittent signal).

The areas limited in the graphs by the black lines show a $95 \%$ certainty of red noise. The areas below the thin Ushaped line mean the cone of influence below which the edge effect is dominant so the results may not be reliable and should be applied with caution [20]. The period for the results in this area is less than 256.

Cycle-to-cycle variation in combustion occurs simultaneously in several different time scales as a result of nonlinear factors. Longer injection time results in oscillations to occur in a period ranging from 10 to 100 cycles. Such oscillations do not occur if mixture composition in the other cylinders remains the same.

\section{Summary}

A mathematical analysis of time series proves that if there are controlled disturbances in mixture composition in a single cylinder, certain cylinders only are responsive. Cylinders 3, 5, 7 and 9 are most responsive to disturbances, which proves that they show the least cycle-to-cycle variation in combustion. Cyclical modification in mixture composition are able to increase critical indicators of a multifractal analysis, i.e. a level of variation correlation and a complexity of its response). A wavelet analysis confirms graphically that combustion in cylinders supplied by a disturbed mixture is complex. There are significant differences in the level of cyclical variation in combustion in a single cylinder, which has an impact on a level of cycle-to-cycle variation in operation of the entire engine.

The methods to investigate a dynamic response of a system used in internal combustion engines need to be tested in other types of engines and for a different option of mixture composition disturbance to evaluate all of their advantages, typical irregularities in combustion. Investigating thoroughly the position of parameters of a multifractal spectrum/area for each time series of a given cylinder can be helpful in identifying and diagnosing an incorrectly operating cylinder. 


\section{Nomenclature}

MF multifractal analysis

CWT continous wavelet transform

IMEP mean indicated effective pressure

SI spark ignition $\lambda \quad$ air-fuel ratio

WPS wavelet power spectrum

\section{Bibliography}

[1] BERCKÜLlER, M., TAIL, N.P., GREENHALGH, D.A. The influence of local fuel concentration on cyclic variability of a lean burn stratified-charge engine. SAE Technical Paper. 1997, 970826.

[2] CZARNIGOWSKI, J., WENDEKER, M., JAKLIŃSKI, P. et al. Testing non-uniformity of the combustion process in a radial aircraft engine. SAE Technical Paper. 2007, 2007-012074.

[3] DAW, C.S., FINNEY, C.E., KENNEL, M.B. Symbolic approach for measuring temporal "irreversibility". Physical Review E 62. 2000, 2, 1912-1921.

[4] DAW, C.S., KENNEL, M.B., FINNEY, C.E.A., CONNOLLY, F.T. Observing and modeling nonlinear dynamics in an internal combustion engine. Phys. Rev. E. 1998, 57, 28112819.

[5] FOAKES, A.P., POLLARD, D.C. Investigation of a chaotic mechanism for cycle-to-cycle variations, Combustion Science and Technology.1993, 90, 281-287.

[6] GECA, M., LITAK, G., CZARNIGOWSKI, J., PIETRYKOWSKI, K. Diagnostics of the aircraft radial engine by using Recurrence Plots method. PTNSS CONGRESS 2009, PTNSS-2009-SC-058, 133-140.

[7] GOLDBERGER, A.L. AMARAL, L.A.N., GLASS, L. et al. PhysioBank, physioToolkit, and physioNet components of a new research resource for complex physiologic signals, Circulation. 2000, 101, E215, and the software provided on the webpage www.physionet.org/physio-tools/multifractal/

[8] HEYWOOD, J.B. Internal Combustion Engine Fundamentals, MCGraw-Hill Science Engineering. 1988.

[9] HU, Z. Nonlinear instabilities of combustion processes and cycle-to-cycle variations in spark-ignition engines, SAE paper. 1996, 961197.

[10] JAKLIŃSKI, P., WENDEKER, M., CZARNIGOWSKI, J. et al. Analiza ciśnienia indykowanego w gwiazdowym tłokowym silniku lotniczym zasilanym benzyną lotniczą 100LL i benzyną samochodową ES95, Silniki spalinowe. 009-SC2 Seria Specjalna, 2009, 162-170.

[11] KANTOR, J.C. A dynamical instability of spark-ignited engines, Science. 1984, 224, 1233.

\footnotetext{
Gęca Michał, DEng. - Faculty of Mechanical Engineering at the Lublin University of Technology.

e-mail:m.geca@pollub.pl
}

[12] LITAK, G., WENDEKER, M., KRUPA, M., CZARNIGOWSKI, J. A numerical study of a simple stochastic/deterministic model of cycle-to-cycle combustion fluctuations in spark ignition engines. Journal of Vibration and Control. 2005, 11371-11379.

[13] LONGWIC, R., SEN, A.K., GÓRSKI, K. et al. Cycle-tocycle variations of the combustion process in a Diesel engine powered by different fuels. Journal of Vibroengineering. 2011, 13, 120-127.

[14] MIKALSEN, R. ROSKILLY, A.P. A computational study of free-piston diesel engine combustion. Applied Energy. 2009, 86, 1136-1143.

[15] MOULIN, P., CORDE, G. CHAUVIN, J., CASTAGNÉ, M. Cylinder individual AFR estimation based on a physical model and using Kalman filters. SAE Technical Paper. 2004, 2004-01-422.

[16] MUZY, J.F., BACRY, E., ARNEODO, A. Multifractal formalism for fractal signals: The structure-function approach versus the wavelet-transform modulus-maxima method, Phys. Rev. 1993, E 47, 875-884.

[17] NEWLAND, D.E. Practical signal analysis: do wavelets make any difference! Processings of DTC'97 1997 ASME Design Engineering Technical Conference, September14-17, 1997, Sacramento, Kalifornia.

[18] SEN, A. K., LITAK, G., KAMINSKI, T., WENDEKER, M. Multifractal and statistical analyses of heat release fluctuations in a spark ignition engine. Chaos. 18, 1-6.

[19] SZLACHETKA, M., GĘCA, M., WENDEKER, M., STĘPNIEWSKI, A. Badania porównawcze dynamiki filmu paliwowego w stanach dynamicznych silnika zasilanego benzyną oraz alkoholem etylowym, V Konferencja Naukowa Ekoenergia '2010, Materiaty konferencyjne - AUTOBUSY Technika, Eksploatacja, Systemy Transportowe, 2010, 95102.

[20] TORRENCE, C., COMPO, G.P. A practical guide to wavelet analysis, Bull. Amer. Meteor. Soc. 1998, 79, 61-78.

[21] www.optrand.com

[22] www.radialengines.com/fuel_injection/index.htm 